\title{
Hordes of mandrills (Mandrillus sphinx): extreme group size and seasonal male presence
}

\author{
K. A. Abernethy ${ }^{1,2 *}$, L. J. T. White ${ }^{3}$ and E. J. Wickings ${ }^{1}$ \\ ${ }^{1}$ Centre International de Recherches Médicales de Franceville, BP 769, Franceville, Gabon \\ ${ }^{2}$ Department of Biological and Molecular Sciences, University of Stirling, Stirling FK9 4LA, Scotland, U.K. \\ ${ }^{3}$ Wildlife Conservation Society, Bronx, NY 10460-1099, New York, U.S.A. \\ (Accepted 16 October 2001)
}

\begin{abstract}
Mandrill Mandrillus sphinx hordes in the Lopé Reserve, Gabon, the approximate centre of the mandrill species range, were studied over 3 years from 1996 to 1999. Part of the study site included gallery forests within savanna areas, allowing observation of entire hordes, hitherto impossible in dense forest habitat. Horde size and composition (sex and age classes) were documented using exact records on video film whenever a horde or subgroup crossed an open space. Mean horde size was 620, and hordes of up to 845 individuals were documented, probably the largest stable group size found in any wild, unprovisioned primate population. Hordes were cohesive throughout the study period and did not seem to be aggregations of smaller units. Mandrill societies seem to be quite different from the baboon societies, to which they have been compared to date. Mature, breeding-age males were not resident members of hordes, but entered at the onset of seasonal cycles in the females (as deduced by the presence of sexual tumescence) and emigrated once female sexual cycles ceased. The number of breeding males present in the horde at any one time is best explained by the number of sexually attractive females. It is postulated that the extreme coloration of males and strong sexual dimorphism in mandrills may have evolved through an enhanced need for competitive signals in a situation where no long-term social bonds between breeding partners exist.
\end{abstract}

Key words: mandrill, Mandrillus sphinx, group size, social organization, Gabon

\section{INTRODUCTION}

Mandrills Mandrillus sphinx are found only in the rain forests of central Africa from Cameroon, south of the Sanaga River, through Equatorial Guinea and Gabon, to southern Congo, west of the Congo River (see Fig. 1; Harrison, 1988; Blom et al., 1992; Kingdon, 1997). The species is recognized by IUCN as near-threatened (Baillie \& Groombridge, 1996; Oates, 1996), a classification awarded because of its limited geographic distribution, known human hunting pressure and habitat loss throughout the range. Very little is understood about mandrills in the wild. Only a few short studies have been made and all authors report great difficulty in finding and following mandrills for more than a few days at a time (Sabater Pi, 1972; Jouventin, 1975; Hoshino et al., 1984; Lahm, 1985, 1986; Hoshino, 1986; Harrison, 1988; Rogers et al., 1996).

*All correspondence to: $\mathrm{K}$. Abernethy, Centre International de Recherches Médicales de Franceville, BP 769, Franceville, Gabon. E-mail:wcsgabon@uuplus.com
Mandrills are among the largest of the cercopithecine primates. Morphologically they are similar to baboons (Papio spp. and Theropithecus gelada) and like the baboons they are mainly ground dwelling, omnivorous and eclectic in diet and highly social. These characteristics led, until recently, to taxonomic classification of the Mandrillus species with the baboons. However, contemporary genetic and morphological studies show convincingly that Mandrillus species are more similar to the terrestrial Cercocebus mangabeys (Disotell, 1993; Fleagle \& McGraw, 1999). The previous grouping of Mandrillus with Papio led to the interpretation of the scant data on wild mandrills in terms of the patterns of social organization described for baboon societies, e.g. patterns described by Altmann \& Altmann (1970) or Kummer (1995). Mandrills have generally been represented as living in one male units (a dominant breeding male with a multifemale harem) occasionally aggregating to form large multi-male hordes (Sabater Pi, 1972; Jouventin, 1975; Rogers et al., 1996)

Visibility is poor in the mandrill's habitat and much of the published data on group structure has been based 


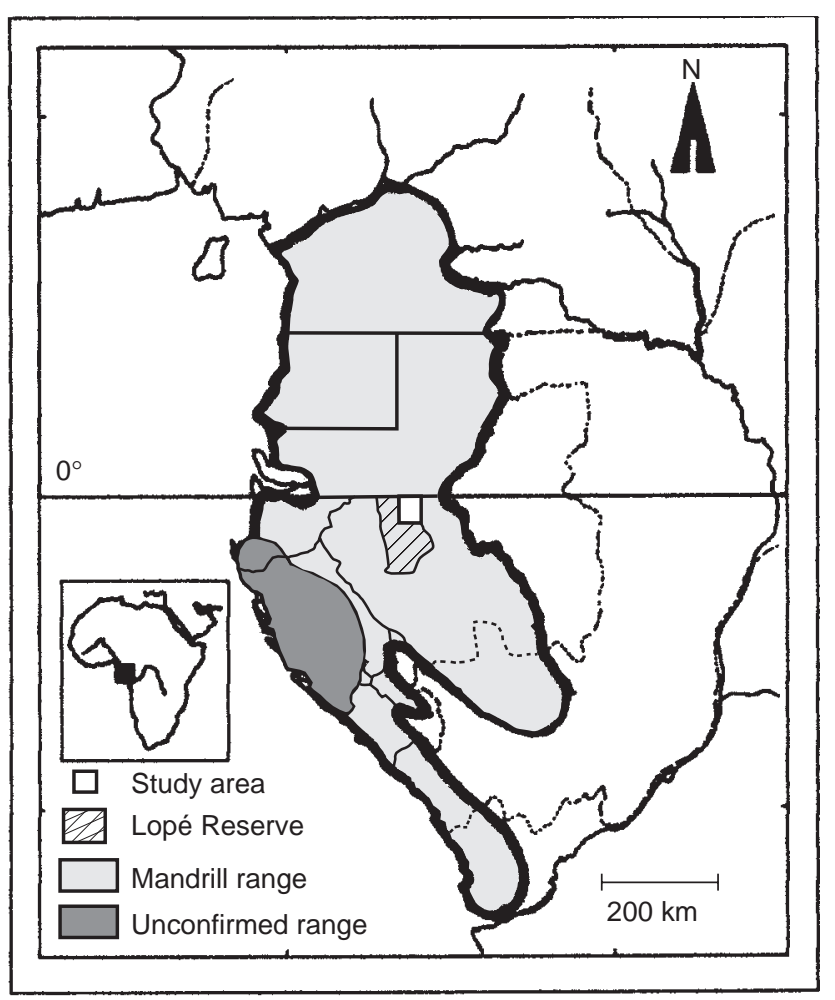

Fig. 1. The current geographic range of Mandrillus sphinx. The Lopé study area is in the approximate centre. The existence of mandrills in the coastal area between the Equator and the Monts Doudou is possible, but their presence is currently unconfirmed. Sources: Grubb (1973); Harrison (1988); Blom et al. (1992); Idiata, Mbina \& Mihindou (2000).

on estimated group compositions (Sabater Pi 1972; Jouventin, 1975; Harrison, 1988; Ancrenaz, Tutin \& Fernandez, 1994). No study has yet been able to provide a precise breakdown of group composition, nor include data on seasonal changes in mandrill societies.

In this paper, new data are presented on the composition and social organization of mandrill hordes from a 4-year study in the Lopé Reserve, Gabon. These data show that mandrills live in much larger and more stable societies than previously documented, forming the largest permanent groups of any wild primate. It is shown that the social organization of wild mandrill hordes in central Gabon does not follow any of the models proposed for baboon societies, nor is it very similar to any other cercopithecine social system yet described. A novel explanation is presented for mandrill social organization and the implications of the new data in the evolution of the mandrill phenotype are discussed.

Mandrills congregate in large numbers, variously referred to in past literature as 'groups', 'supergroups' or 'hordes' (Ancrenaz et al., 1994; Rogers et al., 1996). Here, the term 'horde' is used for a known, stable aggregation of mandrills. The term 'group' may refer to any number of individuals together, for any reason, and is therefore not used to indicate the stable social unit.

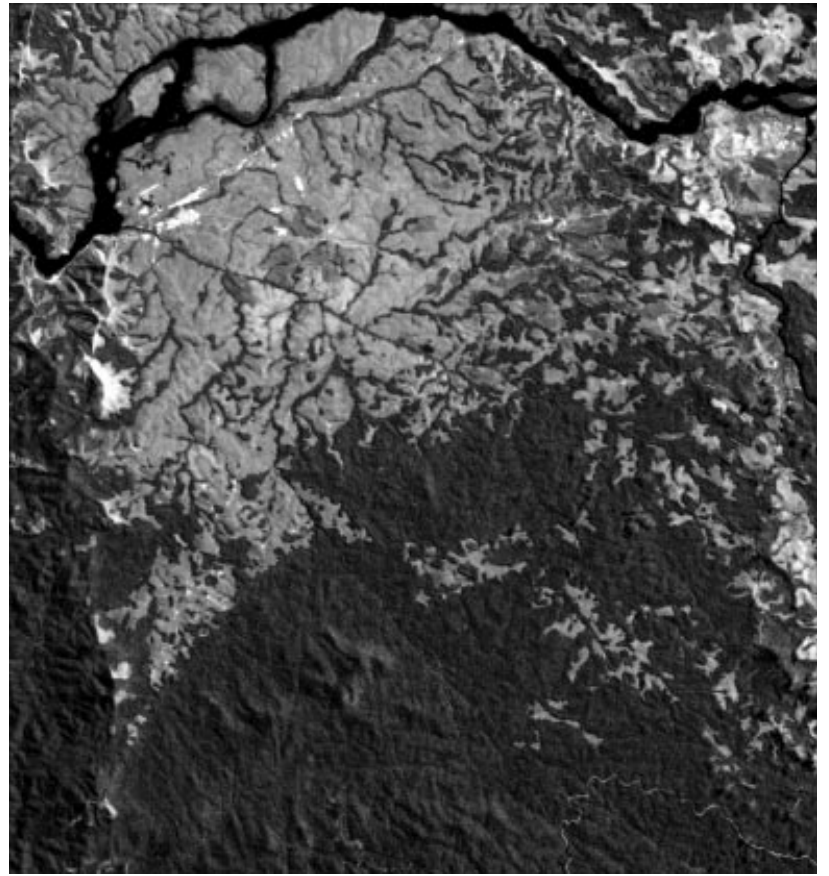

Fig. 2. Vegetation map of the northern part of the study area at Lopé, showing the Ogooué River at the north edge. 'Gallery' forests form thin corridors along watercourses in the savanna areas. Supervised visual interpretation from ERS radar image 1996, Universal Transverse Mercator, Zone 32S, WGS 84

\section{METHODS}

\section{Study area}

The ongoing study of mandrill ecology is based in the area around the Station d'Etudes des Gorilles et Chimpanzés (SEGC) in the northern part of the Lopé Reserve, central Gabon (0012S, 1136E). This is roughly in the centre of the species range (see Fig. 1). The region to the south of the SEGC research station is continuous semi-deciduous Guineo-Congolian lowland rainforest. However, for $15 \mathrm{~km}$ to the north, the vegetation is a mosaic of ancient savanna grasslands and natural forest fragments, bordered by the Ogooue River which is a natural barrier to most terrestrial mammals (Fig. 2). The thin corridors of forest within the savanna regions afford a unique opportunity to observe all members of a group as they travel along the corridor. These detailed observations are impossible in areas of continuous forest where many individuals moving in a widely dispersed group are hidden by dense ground cover. The vegetation of the Reserve is described in detail by White (1995); White \& Abernethy (1997) and White et al. (in press). Annual rainfall at SEGC is $1509 \mathrm{~mm}$ (1984-99) and the region experiences 2 dry seasons a year: a variable 'short' dry spell of 3-6 weeks during December-February and a long dry season of c. 3 months from mid-June to mid-September. Temperatures vary little through the year with mean 
monthly minima of $20-23{ }^{\circ} \mathrm{C}$ and maxima of $26-33^{\circ} \mathrm{C}$ (1984-98), but are lowest during July-August.

\section{Observations and follows}

Hordes of mandrills, numbering several hundred individuals, were first documented at Lopé in 1995 (Rogers et al., 1996; Tutin, White \& Mackanga-Missandzou, 1997). Throughout the 39-month period from June 1996 to August 1999, foot patrols of the forested parts of the study area were made on 5 days/week, such that the whole area was covered every 2 weeks. A daily drive ( 5 days in 7) was also made through the forest-savanna mosaic area. Mandrills were located by sight, or by the long-distance contact calls of the females, which carry up to $1 \mathrm{~km}$ across savanna areas and several hundred metres even within the forest. No attempt was made to follow lone males, but groups were followed for as long as possible on each occasion.

Reliable counts of group members proved impossible within the forest, so observers were stationed at a hidden position in front of the group, to record them as they crossed an open area. Evidently these special circumstances required for accurate counts meant that a horde count was not possible on each occasion that mandrills were encountered. A permanent record of each horde was made on video film as well as a direct observer count (no permanent record) whenever they were observed crossing an open area. Only film records including every member of the group were used in the current analyses of group size and composition. However, as mature males are not numerous and were easily identified, numbers of mature males in the group could sometimes be counted, even when a total record of other members was not possible. All mature male counts are used in the analysis of their seasonal presence. Each film record was analysed by at least 2 observers, who noted the sex and age class of each animal. Observers were trained by watching a captive group of known-age mandrills in a semi-free ranging colony at the Centre International de Recherches Médicales de Franceville in Gabon (for a description of this colony see Feistner \& Cooper, 1986; Wickings \& Dixon, $1992 a$ ). Inter-observer reliability was also tested in 'blind' trials on these animals. A computer program ('Mandrill'; P.Walsh, 1998), was developed to analyse video film frame-by-frame, to maximize the accuracy and repeatability of counts.

Individuals were assigned to the following age-sex classes, which were found to be reliably differentiated by observers trained on the captive colony: infant ( 0 12 months), juvenile (13-36 months), adult female (>3 years), 5- to 6-year-old male, sub-mature (6- to 9year-old) male and mature male. Of course, it is not known whether physical characters develop at the same rate in the field as in captivity. The years attributed to age-sex classes here must be viewed as an approximate guide. Captive males attain full size and coloration at c. 10 years old (sexual maturity) and thereafter physical appearance changes little with age (Wickings \& Dixon, $1992 a$ ). As the exact age of coloured males could not be further determined in the field, they were pooled into 1 class: mature males. Within the adult female class, females carrying ventral infants and those with sexual swellings were noted separately. Sexual receptivity in female mandrills is signalled, as in many primates, by sexual tumescence: the swelling and reddening of the skin around the anus and vulva. This is easily visible in films shot at close range and was reliably scored for the groups encountered from June 1997 to August 1999.

Males of 3 and 4 years are indistinguishable from adult females in the colony when observed from $50 \mathrm{~m}$ or more, and are rarely distinguishable in the field. These young males were necessarily included in the adult female class in the initial video analysis. Males $>5$ years are identifiable in the field. A correction for the number of 3- to 4-year-old males included in the adult female class was subsequently made as follows. A sex ratio of 1:1 at birth was assumed (observed in the CIRMF colony; Wickings \& Dixon, 1992a) and equal mortality of each sex during the first 3 years of life (which may slightly underestimate the number of males surviving in these cohorts; Dittus, 1980). The number of 2-year-old males is then $1 / 4$ of the total juvenile cohort ( 2 sexes over 2 years). The mid-point between the 2-year-old and the 5-year-old male cohort sizes was then calculated and this was approximated as representing the mean size of both the 3- and 4-year-old cohorts.

Any decline in male cohort size under 6 years is assumed to result from mortality. Field observations of lone males indicate that males $>6$ years old may emigrate from the group, thus the decline in cohort size will reflect a combination of emigration and mortality.

\section{RESULTS}

\section{Group size}

Mandrills were encountered on 41 occasions in 27 different months throughout the study period. In months when they were not encountered, they were assumed to have ranged outside the searched study area (Fig. 2). A record of all horde members was possible on 20 different occasions in 14 different months (Table 1). These 20 full counts include at least four, and probably more, different hordes. On most occasions we were unsure of the identity of the mandrills and could not assign the count with certainty to a particular, named horde. The exceptions are the two counts in July 1997, known to be the same horde ('Crete horde'), and the two counts in early December 1998, known to be 'Walt's horde'; a different one from that counted in July 1997. In the absence of certain identifications, all counts are treated here as individual assessments of horde size, however, the likelihood of several repeat counts in the measure may mean that true variation in horde sizes is found in future to be greater than currently reported. Slight variation between counts of the same horde on 
Table 1. Group sizes and age-sex structures of the Mandrillus sphinx hordes filmed at Lopé between September 1996 and August 1999

\begin{tabular}{|c|c|c|c|c|c|c|c|c|c|c|c|c|c|c|c|}
\hline \multirow{3}{*}{$\begin{array}{l}\text { Date } \\
\text { filmed }\end{array}$} & \multirow{3}{*}{$\begin{array}{l}\mathrm{Gr} \\
\text { size }\end{array}$} & \multirow{2}{*}{\multicolumn{2}{|c|}{$\begin{array}{l}0-12 \\
\text { months }\end{array}$}} & \multirow{2}{*}{\multicolumn{2}{|c|}{$\begin{array}{l}1-2 \text { year } \\
\text { olds }\end{array}$}} & \multirow{2}{*}{\multicolumn{2}{|c|}{$\begin{array}{l}\text { Adult } \\
\text { females }\end{array}$}} & \multicolumn{8}{|c|}{ Males } \\
\hline & & & & & & & & \multicolumn{2}{|c|}{ 3-4 years } & \multicolumn{2}{|c|}{5 years } & \multicolumn{2}{|c|}{$6-9$ years } & \multicolumn{2}{|c|}{$>10$ years } \\
\hline & & $n$ & $\%$ & $n$ & $\%$ & $n$ & $\%$ & $n$ & $\%$ & $n$ & $\%$ & $n$ & $\%$ & $n$ & $\%$ \\
\hline 4 Sep 96 & 609 & 107 & 17.6 & 210 & 34.5 & 158 & 25.9 & 78 & 12.7 & 25 & 4.1 & 14 & 2.3 & 17 & 2.8 \\
\hline 16 Nov 96 & 646 & 96 & 14.9 & 123 & 19.0 & 288 & 44.6 & 64 & 9.9 & 33 & 5.1 & 27 & 4.2 & 15 & 2.3 \\
\hline 27 Jun 97 & 817 & 156 & 19.1 & 245 & 30.0 & 210 & 25.7 & 116 & 14.2 & 55 & 6.7 & 24 & 2.9 & 11 & 1.3 \\
\hline 28 Jun 97 & 791 & 136 & 17.2 & 247 & 31.2 & 222 & 28.1 & 109 & 13.7 & 47 & 5.9 & 17 & 2.1 & 13 & 1.6 \\
\hline 2 Jul 97 & 845 & 173 & 20.5 & 226 & 26.7 & 272 & 32.2 & 95 & 11.2 & 38 & 4.5 & 26 & 3.1 & 15 & 1.8 \\
\hline $10 \mathrm{Jul} 97$ & 815 & 154 & 18.9 & 247 & 30.3 & 238 & 29.2 & 102 & 12.5 & 40 & 4.9 & 25 & 3.1 & 11 & 1.3 \\
\hline 28 Jan 98 & 681 & 175 & 25.7 & 182 & 26.7 & 236 & 34.7 & 62 & 9.0 & 16 & 2.3 & 10 & 1.5 & 1 & 0.1 \\
\hline 11 Feb 98 & 775 & 165 & 21.3 & 247 & 31.9 & 232 & 29.9 & 93 & 12.0 & 31 & 4.0 & 6 & 0.8 & 1 & 0.1 \\
\hline 23 Feb 98 & 711 & 95 & 13.4 & 268 & 37.7 & 229 & 32.2 & 85 & 12.0 & 18 & 2.5 & 14 & 2.0 & 2 & 0.3 \\
\hline 12 Jun 98 & 411 & 58 & 14.1 & 142 & 34.5 & 128 & 31.1 & 50 & 12.0 & 14 & 3.4 & 13 & 3.2 & 6 & 1.5 \\
\hline 5 Sep 98 & 340 & 38 & 11.2 & 100 & 29.4 & 100 & 29.4 & 42 & 12.4 & 17 & 5.0 & 20 & 5.9 & 13 & 3.8 \\
\hline 20 Oct 98 & 338 & 36 & 10.7 & 113 & 33.4 & 98 & 29.0 & 51 & 15.2 & 23 & 6.8 & 15 & 4.4 & 2 & 0.6 \\
\hline 3 Nov 98 & 395 & 47 & 11.9 & 148 & 37.5 & 94 & 23.8 & 62 & 15.7 & 25 & 6.3 & 15 & 3.8 & 4 & 1.0 \\
\hline 30 Nov 98 & 397 & 60 & 15.1 & 130 & 32.7 & 97 & 24.4 & 53 & 13.2 & 20 & 5.0 & 19 & 4.8 & 3 & 0.8 \\
\hline 5 Dec 98 & 551 & 71 & 12.9 & 200 & 36.3 & 130 & 23.6 & 82 & 14.9 & 32 & 5.8 & 16 & 2.9 & 1 & 0.2 \\
\hline 8 Dec 98 & 575 & 11 & 1.9 & 252 & 43.8 & 188 & 32.7 & 87 & 15.1 & 24 & 4.2 & 10 & 1.7 & 2 & 0.3 \\
\hline 22 Dec 98 & 664 & 9 & 1.4 & 340 & 51.2 & 160 & 24.1 & 113 & 17.0 & 28 & 4.2 & 13 & 2.0 & 1 & 0.2 \\
\hline 1 Feb 99 & 689 & 35 & 5.1 & 295 & 42.8 & 158 & 22.9 & 122 & 17.7 & 48 & 7.0 & 30 & 4.4 & 1 & 0.1 \\
\hline 6 Jun 99 & 747 & 155 & 20.7 & 216 & 28.9 & 199 & 26.6 & 92 & 12.3 & 38 & 5.1 & 32 & 4.3 & 15 & 2.0 \\
\hline 9 Aug 99 & 607 & 79 & 13.0 & 192 & 31.6 & 196 & 32.3 & 73 & 12.0 & 25 & 4.1 & 31 & 5.1 & 13 & 2.1 \\
\hline Mean & 620.2 & 92.8 & 14.3 & 206.2 & 33.5 & 181.7 & 29.1 & 81.4 & 13.2 & 29.9 & 4.9 & 18.9 & 3.2 & 7.4 & 1.2 \\
\hline SD & 166.3 & 56.4 & 6.3 & 64.8 & 7.0 & 60.3 & 5.1 & 24.0 & 2.2 & 11.5 & 1.3 & 7.6 & 1.4 & 6.1 & 1.0 \\
\hline
\end{tabular}

different dates may be explained by birth or mortality (especially among infants), male immigration and emigration and exceptionally by some animals being missed on film. Splitting off of small sub-groups was never observed, though hordes were observed being forced to divide when their passage across an open space was disrupted. On these occasions the horde always reunited within a few days, but for unknown groups it is possible that fractions of a disrupted horde were counted as a total horde in error during this period.

The mean number of individuals was $620.2 \pm 166.3$, range $340-845$ (see also Table 1). Although exact counts could not be made during the remaining 21 encounters, field observers established minimum counts for these hordes, the least of which was 425 individuals. As mature males are so large and easily distinguishable, they were reliably counted on four of these occasions, even though total group counts were not possible.

Mature males were encountered in hordes with females and young, or as solitary individuals, but never in bachelor groups.

\section{Group composition}

The composition of each of the filmed groups, including the corrections for 3- and 4-year-old males originally assigned to the adult female class, is shown in Table 1.

Adult females and their dependent offspring (infants, juveniles and <6-year-old males) formed $96 \%$ of the group (mean $96.1 \pm 2.6$ ) and the remaining $4 \%$ included sub-mature and mature males. Five-year-old males were assumed to be permanent group members as they were never seen as solitary individuals. The size of the 5-yearold class showed a positive Spearman correlation with group size $\left(\right.$ d.f. $\left.=20, r_{\mathrm{s}}=0.616, P<0.01\right)$ consistent with this hypothesis.

Females and immature classes were relatively stable throughout the year, but for males over 6 years old, group membership fluctuated greatly between months. When tested across all months the number of $>6$-yearold males present in a group was independent of group size for either sub-mature or mature males (d.f. $=20, r_{\mathrm{s}}$ $($ sub-mature $)=0.164, P<0.5, \mathrm{NS} ; r_{\mathrm{s}}$ (mature $)=0.173$, $P<0.5$, NS).

Mature males were counted in the groups in 22 out of the 39 months. In two counted months, no mature males were present in the groups (April and May 1998; Fig. 3).

\section{Mating seasons}

The presence of females with sexual swellings in a group was used to divide the observations into those when mating was taking place and those outside the mating season. Only 18 counts were used as the two films shot in 1996 were not of sufficient quality to score tumescence reliably. Mating seasons were found to be annual, with sexual swellings seen only from June to November in any of the 3 years 1996-98 and May-October 1999. Group size was independent of reproductive activity (mean group size $=610.6$ in mating months and 630 in other months, $t_{\text {unmatched }}=0.241$, d.f. $=16, \mathrm{NS}$ ). 


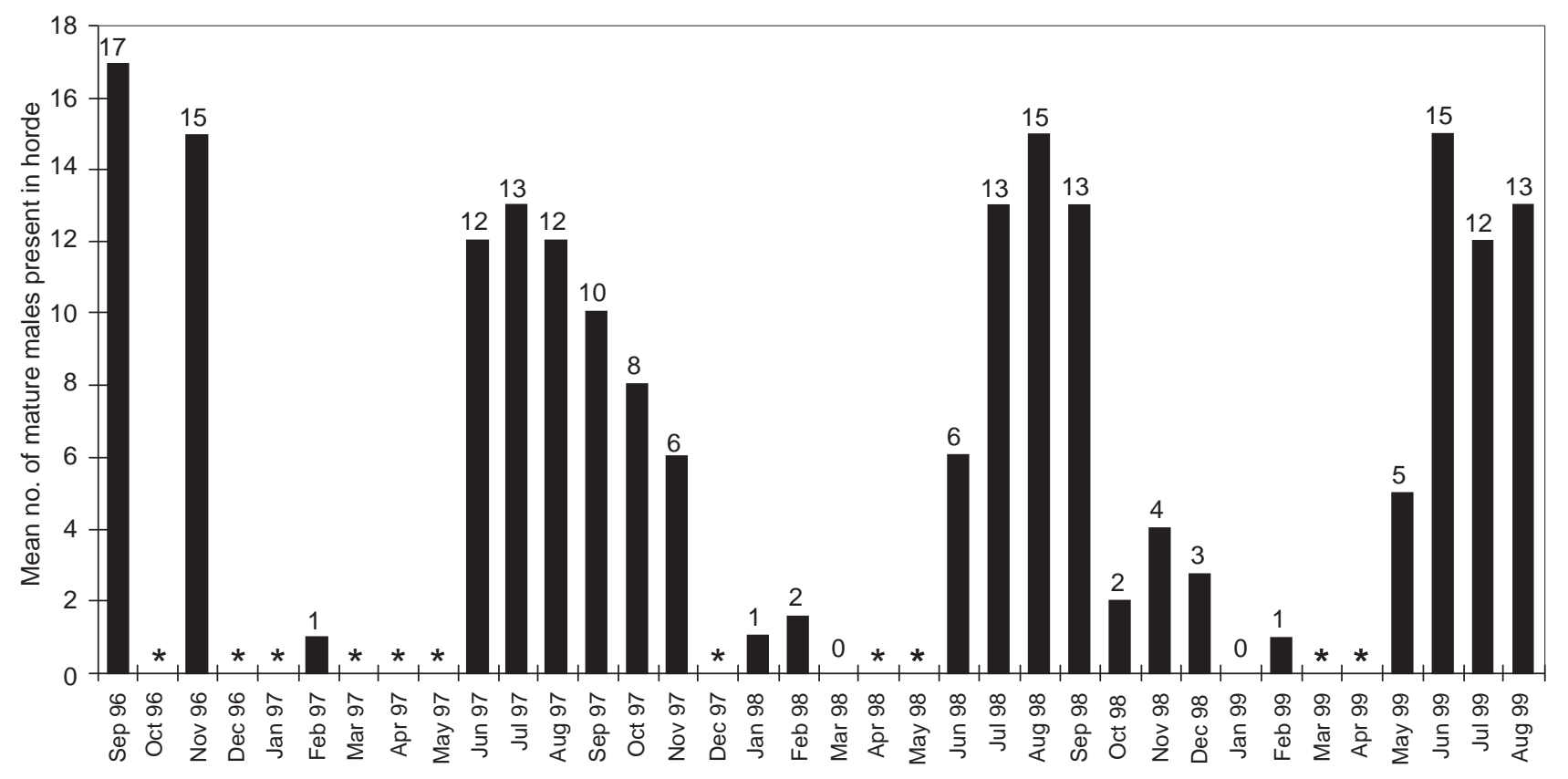

Fig. 3. Seasonal presence of mature Mandrillus sphinx males in the hordes. Data from 20 full counts and four additional counts when mature males were reliably scored, although total numbers were not able to be accurately recorded. ${ }^{*}$, month for which no data were recorded.

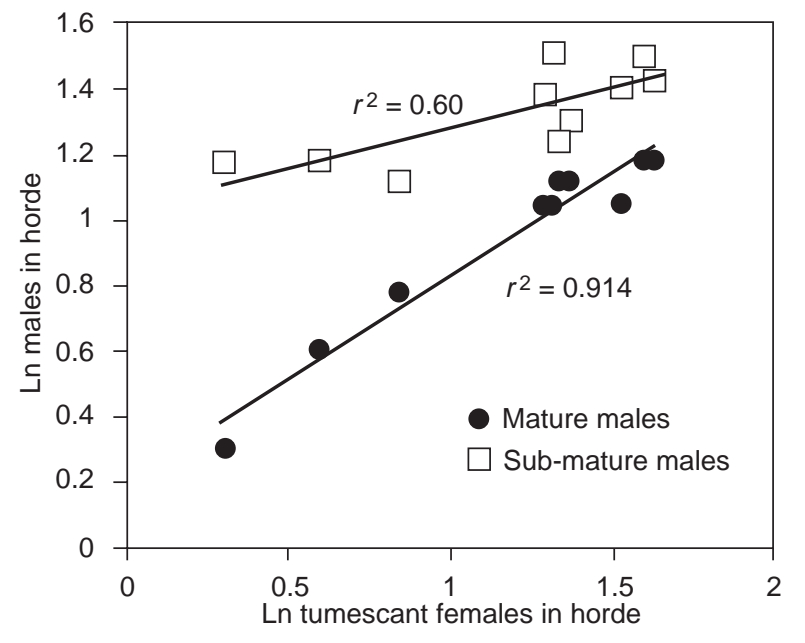

Fig. 4. The relationship between mature and sub-mature Mandrillus sphinx male numbers in the hordes and female sexual receptivity, as denoted by sexual tumescence. Data from the 10 full horde counts during mating seasons where female tumescence was visible.

Mature and sub-mature males emigrated from the group outside the mating season. Whilst group size remained stable, the mean number of mature males in the groups dropped from $9.4 \pm 4.7$, in mating months, to $1.5 \pm 0.8$ in other months, a sixfold difference.

Male numbers were not correlated to total group size even within the mating season months (d.f. $=10$, $r_{\mathrm{s}}=0.568, P<0.2$, NS), but were highly positively correlated to the number of females with visible sexual tumescence. Within the 10 mating season counts, these relationships were best described by logarithmic curves
(Fig. 4). After natural log (Ln) transformation, a Pearson moment correlation showed strong associations between tumescent females and mature males $\left(r^{2}=0.951, P<0.001\right)$ and also slightly weaker associations between the sub-mature male class and these females $\left(r^{2}=0.600, P<0.01\right)$. Mature males enter and leave the group during the mating season, with the numbers present on any 1 day being dependent on the number of tumescent females.

\section{DISCUSSION}

The data presented above document a much larger average group size for mandrills than previous authors have described for any wild primate (Jouventin, 1972; Sabater Pi, 1975; Hoshino et al., 1984; Harrison, 1988; White, 1994).

Two possible explanations exist for the difference between past published group sizes and the new data: (1) group sizes at Lopé are exceptionally large; (2) other authors underestimated group size. Other authors have presented estimates for groups numbering several hundred from various different locations, (Jouventin, 1972; Hoshino, 1984; Hoshino et al., 1985; Lahm, 1986; Harrison, 1988), and have visited Lopé without noting great differences in group size, so it seems unlikely that Lopé is exceptional. As few previous studies have detailed their methods for group size estimation, it is difficult to assess their accuracy, but when a film record cannot be made, accurate counts are unlikely. In our study, when recording video film, a second count by direct observation was attempted in case of problems with the film apparatus. Observers 
generally were only able to count $c .60 \%$ of the true group size. The number of animals visible on encountering a group of known size in the forest was also noted. A maximum of 26 individuals was seen during such a scan, and a mean of 6.1 , representing only $1.2 \%$ of the actual group. It thus seems probable that groups could be seriously underestimated in forest using methods other than film records and that this may explain all, or at least part, of the discrepancy between existing data and the new Lopé data. Clearly an effort to census mandrill hordes using the new film methods over a much wider area will be necessary to confirm how representative Lopé really is.

Groups of females and dependent offspring are cohesive throughout the year, but male presence is seasonal. A regular pattern of mature and sub-mature male immigration and emigration was repeated over the 4 years of the study and is best explained by changes in female attractiveness and receptivity. Males are solitary when outside the horde and enter and leave independently. Bachelor groups have never been seen.

There is no evidence in the wild mandrill hordes of baboon-like 'one male units'. Small, stable groups with a single mature male were never found, although occasionally hordes were forced to split if they were interrupted crossing an open space. On these occasions, the two parties always reunited after a few days. Male numbers were not correlated to horde size, as would be expected if hordes were aggregations of one-male units. As most males are absent from the horde during half the year, it seems highly unlikely that they play any role in horde cohesion, protection or leadership of sub-units within the horde. The organization of mandrill hordes seems to be as a female-led society, in which males play a peripheral role.

Unlike the breeding behaviour documented in most cercopithecine societies, mature male mandrills interact socially with other mandrills only when mating is underway, thus they cannot form the long-term social bonds typical of the lives of most adult cercopithecines (for review of primate societies see Smuts et al., 1987 or Fleagle et al., 1999). At the start of the mating season, males return to the horde subsequent to the onset of sexual cycling amongst females, hence, mating opportunities are immediate and any partner choice must be exercised quickly. Darwin (1871) noted that 'no other member in the whole class of mammals is coloured in so extraordinary a manner as the male mandrill' and mandrills have also one of the largest sexual dimorphisms of the primates, with males weighing more than three times the average female body weight (Wickings \& Dixon, 1992b). Male mandrills have evolved heavy investments in visual, auditory and olfactory displays. Not only the bright colours and large size, but also an intense grunting vocalization emitted by the breeding males when in the presence of tumescent females, and scent marking by rubbing trees against glands in the chest (Wickings \& Dixon, 1992a; Wickings, Bossi \& Dixon, 1993). In wild males, grunting may be continuous for up to 12 $\mathrm{h} /$ day, whenever they are in the presence of sexually receptive females in a horde, which may be 6 consecutive months for a male who joins the horde for the entire mating season. It seems probable that the development of these costly displays must be of ultimate benefit to lifetime reproductive success, either by their influence on female mate choice, or male-male competition (or both).

In captive mature male mandrills, plasma testosterone is correlated to the intensity of skin coloration and body bulk, the frequency of grunting and to ultimate reproductive success. The colours of captive males are brightest when they are dominant and have had most reproductive success (Wickings et al., 1993). Wild males display equivalent bright coloration to captive males, and emit grunts throughout the time they are with receptive females, but not once they are solitary, even if this occurs within the mating season months. In captive mandrills, testosterone levels and skin colour intensity of subordinate males can be inhibited by the presence of a dominant individual (Wickings et al., 1993) suggesting that the evolution of the coloration of the mature male mandrill has probably been driven at least in part by intrasexual competition.

The pressure on the itinerant males to impose dominance on rivals and potential mates without lengthy social interactions, as in most other primates (for reviews see Smuts, 1985; Fleagle et al., 1999), is intense. The founding of success on display, rather than investment in social interactions, could explain the evolution of these extreme secondary sexual characters.

\section{Acknowledgements}

We thank M. Emile Mamfoumbi-Kombila, Directeur de la Faune et Chasse du Ministère des Eaux et Forêts du Gabon, for permission to work in the Lopé Reserve and for his enthusiasm and support for our research; Alphonse Mackanga-Missandzou, Esther Ntsame Alloghe, Jean Tondangoye and Simon Angoué, heads of the 'Brigade de Faune' at Lopé during the project, for their help and collaboration in the field: the ecoguides at the Lopé Reserve, la Brigade de Faune de la Lopé, and Aimé Batsielili, Chris Fairgrieve, Gabriella Frediksson, Miguel Léal, Ernestine Ntsame Effa, Natacha Bengone N'ssi, Benoit Nziengui, Liz Rogers, Caroline Tutin, Peter Walsh and especially, Jean-Thoussaint Dikangadissi, Edmond Dimoto, Jean-Gael Emptaz-Collomb, Olivier Houé and William Karesh for help in the field; Joanna Setchell for help in animal identification and useful discussion. The project was financially supported by the Centre International de Recherches Médicales de Franceville, The Wildlife Conservation Society, The Disney Foundation and Edith and John Newberry. We thank Drs Mike Bruford, Stephen Clifford, Liz Rogers, Caroline Tutin, Natasha Shah and two anonymous reviewers for discussion and comments on the manuscript. 


\section{REFERENCES}

Altmann, S. A. \& Altmann, J. (1970). Baboon ecology. Chicago: University of Chicago Press.

Ancrenaz, M., Tutin, C. E. G. \& Fernandez, M. (1994). Observations of wild mandrill groups (Mandrillus sphinx) in central Gabon. Abstracts of the XVth Congress of the International Primatological Society Bali, Indonesia. Madison: IPS.

Baillie, J. \& Groombridge, B. (1996). IUCN red list of threatened animals. Cambridge: IUCN Species Survival Commision.

Blom, A., Alers, M. P. T., Feistner, A. T. C., Barnes, R. F. W. \& Barnes, K. L. (1992). Primates in Gabon - current status and distribution. Oryx 24: 223-234.

Disotell, T. (1993). The phylogeny of old world monkeys. Evol. Anthropol. 5: 18-24.

Dittus, W. J. (1980). The macaques: studies in ecology, behaviour and evolution. In The social regulation of primate populations: 263-286. Lindburg, D. G. (Ed.). New York: Van Nostrand.

Feistner, A. T. C. \& Cooper, R. W. (1986). The establishment of a semi-free-ranging colony of mandrills at CIRMF, Gabon. Primate Rep. 14: 118-119.

Fleagle, J. G. \& McGraw, W. S. (1999). Skeletal and dental morphology supports diphyletic origin of baboons and mandrills. PNAS, USA. 96: 1157-1161.

Fleagle, J. G., Janson, C. \& Reed, K. E. (1999). Primate communities. Cambridge: Cambridge University Press.

Grubb, P. (1973). Distribution, divergence and speciation of the drill and mandrill. Folia Primatol. 20: 161-177.

Harrison, M. J. S. (1988). The mandrill in Gabon's rainforest: ecology, distribution and status. Oryx 22: 218-228.

Hoshino, J. (1986). Feeding ecology of mandrills (Mandrillus sphinx) in Campo Animal Reserve, Cameroon. Primates 27: 248-273.

Hoshino, J., Mori, A., Kudo, H. \& Kawai, M. (1984). Preliminary report on the grouping of mandrills (Mandrillus sphinx) in Cameroon. Primates 25: 297-307.

Idiata, D., Mbina, C. T. \& Mihindou, Y. D. (2000). Inventaires de faune du Complex d'Aires Protégées du Gamba, Gabon. Rapport Finale. Libreville: WWF CARPO.

Jouventin, P. (1975). Observations sur la socio-ecologie du Mandrill. Terre Vie 29: 439-532.

Kingdon, J. (1997). The Kingdon field guide to African mammals. New York: Academic Press.

Kummer, H. (1995). In quest of the sacred baboon: a scientist's journey. Princeton, NJ: Princeton University Press.

Lahm, S. A. (1985). Mandrill ecology and the status of Gabon's rainforests. Primate Conserv. 6: 32-33.

Lahm, S. A. (1986). Diet and habitat preference of Mandrillus sphinx in Gabon: implications of foraging strategy. Am. J. Primatol. 11: 9-26.

Lee, P. C., Thornback, J. \& Bennet, E. L. (1988). Threatened primates of Africa: the IUCN red data book. Gland, Switzerland: IUCN

Oates, J. F. (1996). African primate conservation. Gland, Switzerland: IUCN.

Rogers, M. E., Abernethy, K. A., Fontaine, B., Wickings, E. J., White, L. J. T. \& Tutin, C. E. G. (1996). Ten days in the life of a mandrill horde in the Lopé Reserve, Gabon. Am. J. Primatol. 40: $297-313$.

Rowe, N. (1996). The pictorial guide to the living primates. East Hampton, NY: Pogonias Press.

Sabater Pi, J. (1972). Contribution to the ecology of Mandrillus sphinx Linnaeus, 1758 of Rio Muni (Republic of Equatorial Guinea). Folia Primatol. 17: 304-319.

Smuts, B. B. (1985). Sex and friendship in baboons. New York: Aldine.

Smuts, B. B., Cheney, D. L., Seyfarth, R. M., Wrangham, R. W. \& Strusaker, T. T. (1987). Primate societies. Chicago: University of Chicago Press.

Tutin, C. E. G., White, L. J. T. \& Mackanga-Missandzou, A. (1997). The use by rain forest mammals of natural forest fragments in an equatorial African savanna. Conserv. Biol. 11(5):1190-1203.

Walsh, P. D. (1998). Mandrill. Microsoft Windows 95/98 compatible PC application program. New York: Wildlife Conservation Society.

White, L. J. T. (1995). Vegetation study final report: Réserve de la Lopé, Gabon. Libreville: ECOFAC, AGRECO C. T. F. T.

White, L. J. T. \& Abernethy, K. A. (1997). A guide to the vegetation of the Lopé Reserve, Gabon. New York: Wildlife Conservation Society.

White, L. J. T., McPherson, G., Tutin, C. E. G., Williamson, E. A., Abernethy, K. A., Reitsma, J. M., Wieringa, J. J., Blom, A. \& Harrison, M. J. S. (in press). Plant species of the Lopé Reserve, Gabon, with emphasis on the northern half. Spec. Publ. Mo Bot. Garden.

Wickings, E. J., Bossi, T. \& Dixon, A. F. (1993). Reproductive success in the mandrill, Mandrillus sphinx: correlations of male dominance and mating success with paternity, as determined by DNA fingerprinting. J. Zool. (Lond.) 231: 563-574.

Wickings, E. J. \& Dixon, A. F. (1992a). Testicular function, secondary sexual development and social status in male mandrills (Mandrillus sphinx). Physiol. Behav. 52: 909-916.

Wickings, E. J. \& Dixon, A. F. (1992b). Development from birth to sexual maturity in a semi-free-ranging colony of mandrills (Mandrillus sphinx) in Gabon. J. Repro. Fertil. 95: 129-138. 